\title{
Tooth Socket
}

National Cancer Institute

\section{Source}

National Cancer Institute. Tooth Socket. NCI Thesaurus. Code C94543.

Any of the bone cavities of the mandible or maxilla in which the roots of the teeth are anchored. 